\title{
EFFECT OF TWO DIFFERENT OVERDENTURE ATTACHMENTS ON THE BITING FORCE AND OCCLUSAL FORCE DISTRIBUTION
}

\author{
Mai Adel Helmy ${ }^{*}$ and Marwa Kothayer**
}

\begin{abstract}
Objective: This study compared and evaluated the effect of two different implant retained Mandibular Overdenture attachments on the biting force and occlusal force distribution.

Materials and Methods: Fourteen completely edentulous male patients were selected and two implants were inserted for each patient. After 3 months of installation Patients were randomly divided into two equal groups: Group (I): Patients received conventional complete maxillary dentures opposed by Mandibular over dentures supported and retained by two conventional implants using ball attachment Group (II): Patients received conventional complete maxillary dentures opposed by Mandibular over dentures supported and retained by two conventional implants using locator attachment. Biting force was evaluated using I load star sensor. At time of prosthesis insertion, 3 months, 6 months, 9 months and 12 months. The T-Scan III digital occlusal system was used to record anterior and posterior percentage occlusal force $(\% \mathrm{OF})$ distribution.
\end{abstract}

Results: The result was revealed that there was no statistically significant difference in biting force and occlusal force distribution between the two different attachments (locator attachment and ball attachment) in retained Mandibular Overdenture.

KEY WORDS: Overdenture; biting force; occlusal force distribution.

\section{INTRODUCTION}

The main complaints of patients with severely resorbed mandibles are lack of sufficient stability and retention of their Mandibular dentures. This may attribute to negative functional ability such as esthetics, speech, biting and chewing ability. ${ }^{(1-3)}$ The Implant supported Overdenture was introduced as a recent treatment option that are available to edentulous patients in order to improve the denture retention and stability which directly progress the positive patients reports outcomes in satisfaction, masticatory function and quality of life after receiving implant retained prostheses.$^{(4-6)}$

According to the McGill consensus statement on over dentures, a two -implant Overdenture should become the standard of care of the edentulous

\footnotetext{
* Lecturer, Removable Prosthodontics Department, faculty of dentistry, Cairo University.

** Lecturer, Removable Prosthodontics Department, faculty of dentistry, Ain Shams University.
} 
mandible ${ }^{(7)}$. The improvement of the oral function of implant- retained Mandibular over dentures may depend on the degree of retention and stability of the denture and thus on the type of attachment. An attachment is defined as 'a mechanical device for the fixation, retention, and stabilization of prosthesis. The attachment of implant- retained Overdenture is selected according to the amount of retention needed, available inter arch space, the amount of available bone, patient's social status, patient's expectations, the status of the antagonistic jaw and cost effectiveness ${ }^{(8)}$.

Ball attachments are considered the simplest type and wide spread acting as snap fasteners for use with over dentures supported by endosteal implants in various implant systems. They are resilient attachments and widely available with several advantages; they showed a reasonable success rate as simplest retainers for Mandibular over dentures. ${ }^{(9)}$ They are less cost, less technique sensitive, minimal chair time requirements and easier to clean than bars. Also, the potential for mucosal hyperplasia was reduced with solitary ball attachments. unfortunately, Ball attachments suffer some disadvantages in comparison with other types of attachments such as higher profile design also ball attachments may lead to higher concentration of stress patterns at the neck of the ball transferring a greater amount of stresses to the implant and the underlying bone, Thus reducing retention of the prosthesis due to wear of the rubber O-ring so need for regular servicing of over dentures (10-12)

The locator attachment system has become widely applied. Characterized by extremely low profile design, It was found that low profile design of locator was beneficial and related to the reduction of load transfer to the implant. This can be explained by reducing the lever arm length resulting in a better mechanical advantage.$^{(13-15)}$ Easy seating in the oral cavity by the patient, self-aligning feature allow the ability to fit non-parallel implants up to $40^{\circ} \mathrm{C}$ divergence have been advocated as a suitable alternative to the classical widely used ball attachment. Other studies have reported that the highest retentive force and maintained that force up to $30^{\circ}$ tilting more in locator attachment system when compared to ball system. The rounded edges, "self-aligning feature", decreases the wear of nylon male leading to better durability of the attachment. The double retentive surface area is called "Dual retention" (internal and external features of the abutment) ensuring long-lasting retention life. ${ }^{(16,17)}$

The T-Scan System is a dental device used to analyze the relative occlusal load that is recorded by a pressure mapping sensor intraorally. The system unit include computer software, recording sensor and handle assembly. This system allow computerizing and analysis of the dynamic occlusion by registering parameters such as bite length, force of tooth contact and timing of tooth contact also, the system is able to record the dynamic visual occlusal forces from the initial tooth contact to the maximum intercuspation. ${ }^{(18-21)}$

Biting force is considered as an important parameter to evaluate the efficiency of the dental prosthesis and it also reflect an idea about the temporomandibular disorders and neuromuscular changes. It was reported that the masticatory bite forces with the patients using complete denture is smaller than those produced by natural dentition which is about $200 \mathrm{~N}$, while the maximum bite force have been reported for complete dentures are 60$80 \mathrm{~N}$ and about $150-170 \mathrm{~N}$ for the implant supported Overdenture. ${ }^{(22,23)}$

\section{MATERIALS AND METHODS}

\section{Patient Selection:}

Fourteen completely edentulous male patients age ranged (55-60 year) were selected from those attending the out-patient clinic of Removable Prosthodontics Department, Faculty of DentistryAin Shams University to participate in the study. 


\section{Criteria for Patient Selection:}

- Male patients had completely edentulous maxillary and Mandibular arches.

- Patients age ranges from 55 to 60 years old.

- Patients with good oral hygiene were selected to participate in the study.

- Patients with Angle Class-I Maxillo-Mandibular relationship and sufficient inter-arch spaces were selected.

- Residual alveolar ridges were covered with firm healthy mucosa, free from any signs of inflammation, ulceration or flabbiness.

- Patients with systemic diseases that might affect bone quality, contribute to bone Resorption, increase surgical risk, delay or complicate postoperative healing were excluded

- Patients with any muscular or TMJ disorders and patients with parafunctional habits were excluded.

Diagnostic Panoramic radiographs were made for all patients to evaluate the presence or absence of remaining roots, impactions or any other pathological lesions that might complicate placement of dental implants inter-foraminally, locate the position of mental foramina, level of inferior alveolar canal and detection of anterior looping of mental nerve.

Patients received complete denture constructed by conventional technique and follow up was done for two weeks before surgery.

Dentures were duplicated and four radio-opaque landmarks using Gutta Percha inserted in the holes that was drilled at both premolar areas and both lateral areas in the duplicate denture. Holes containing Gutta Percha was sealed with pink wax. After
CBCT examination, window-like openings in the areas of the proposed implant sites were done to aid in determining proper drilling site.

Patients received conventional complete maxillary dentures opposed by Mandibular over dentures supported and retained by two conventional implants* of $4 \mathrm{~mm}$ diameter and $10 \mathrm{~mm}$ length were placed in the interforaminal region by the of surgical guide and a classical sequential drilling was done after flap reflection.

Patients were recalled after 3 months of osseointegration for the prosthetic phase and Patients were randomly divided into two equal groups:

Group (I): Patients received Mandibular over dentures supported and retained by ball attachments.

Group (II): Patients received Mandibular over dentures supported and retained by locator attachments.

The cover screw was removed and the ball attachment was screwed into the fixture for group 1 patients and locator attachments for group 2 patients and firmly tightened with torque wrench at $30 \mathrm{Ncm}$.

Prior to the pick-up of the metal housings, in both groups, block-out shim was adapted to each abutment to block out the undercut areas inferior to the ball abutments (sub-housing area),

Direct pick up procedure by relieving areas of the fitting surface of the denture over the implant sites and were filled with self-cure acrylic resin. The denture was seated, and the patient was instructed to bite gently on it during the setting of the acrylic resin. After the resin sets the denture was removed and the metal housing inside the denture was examined. Mis-seating of the housing was expected so proper seating of the housings was ensured. Engaging the acrylic resin to the ball attachment undercut was prevented by blocking with pink wax. Figure (1)

* Multisystem implant Italy 


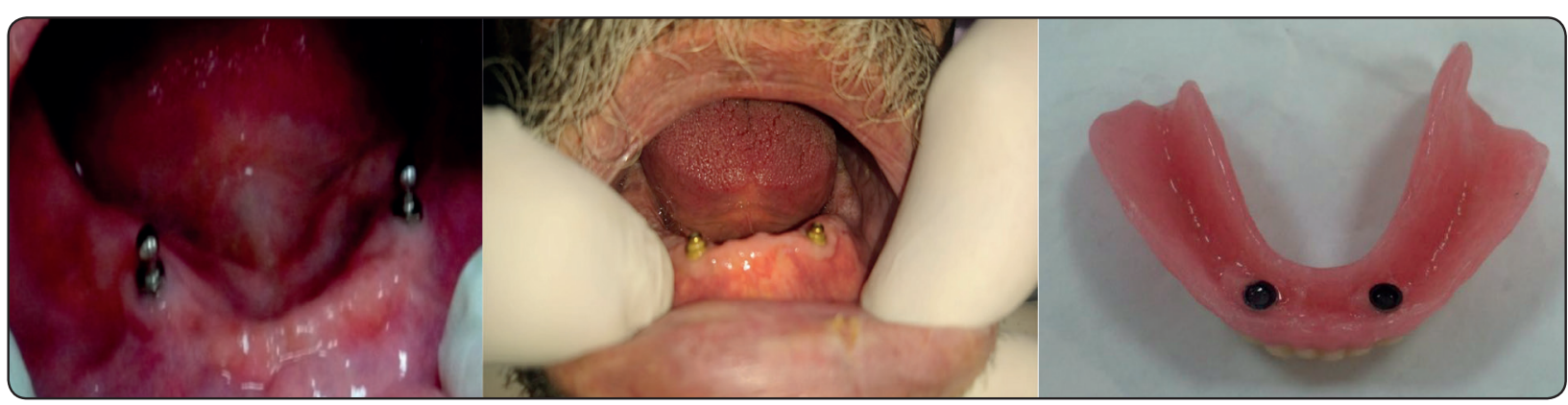

Fig. (1) A, stud attachment , B. locator attachment , C: metal housing for locator attachment.

Selective grinding step was performed intraorally with ordinary articulating paper method in order to create bilateral balance occlusion besides checking the center of force (COF) and trajectory line by the T-scan III *

\section{Occlusal force distribution measurement:}

Occlusal force distribution was done using the T-Scan III device which consists of a sensor registering occlusal contacts, a data transferring module linked to a computer, a software program to send data to the computer and visualize them on the monitor.

The recording procedure is performed inconformity with the manufacturer's instructions of using the device to register occlusal contacts. The patient is seated on the dental chair with the lower and upper parts of his body positioned at an angle of $90^{\circ}$. We used a small 100-micron-thickHD sensor, which is inserted in the sensor handle connected to the scanning handlebar.

The recording sensor is inserted intraorally between the dental arches so that the central mark is positioned between the central incisors of the patient.

The results showing the occlusal forces (in percentages) from first tooth contact through to complete centric intercuspation. The force changes in occlusal contacts are presented in graphical form for each segment during registration of the occlusion.

\section{Occlusion analysis:}

The measurements were obtained from the occlusal data: force distribution in the dental arch, number of teeth that occlude at maximum intercuspation, location of the center of force in the arch to determine the symmetry of the force distribution in the arch.

In order to analyze the T-Scan patterns, the occlusal force information of the arch at maximum intercuspation was grouped into three regions: anterior (canine to canine), posterior right and posterior left (premolar to molars). The force distribution in all three regions was assessed in all participants. Figure (2)

\section{Biting force measurement:}

The Load star sensor** in Newton was used to measure the biting force, it was placed horizontally at the central point of the edentulous ridge on the occlusal surface of the denture teeth and the patient was instructed to clench maximally. The position of the measurement was identical for all dentures by placing the sensor on the first molar area. The biting force was recorded for each side and the highest 5measurements were included in the statistics. Figure (3)

* T scan III (Tesco, South Boston, USA).

** I load digit USB sensor, Loadstar sensor, Mountain View ,CA 


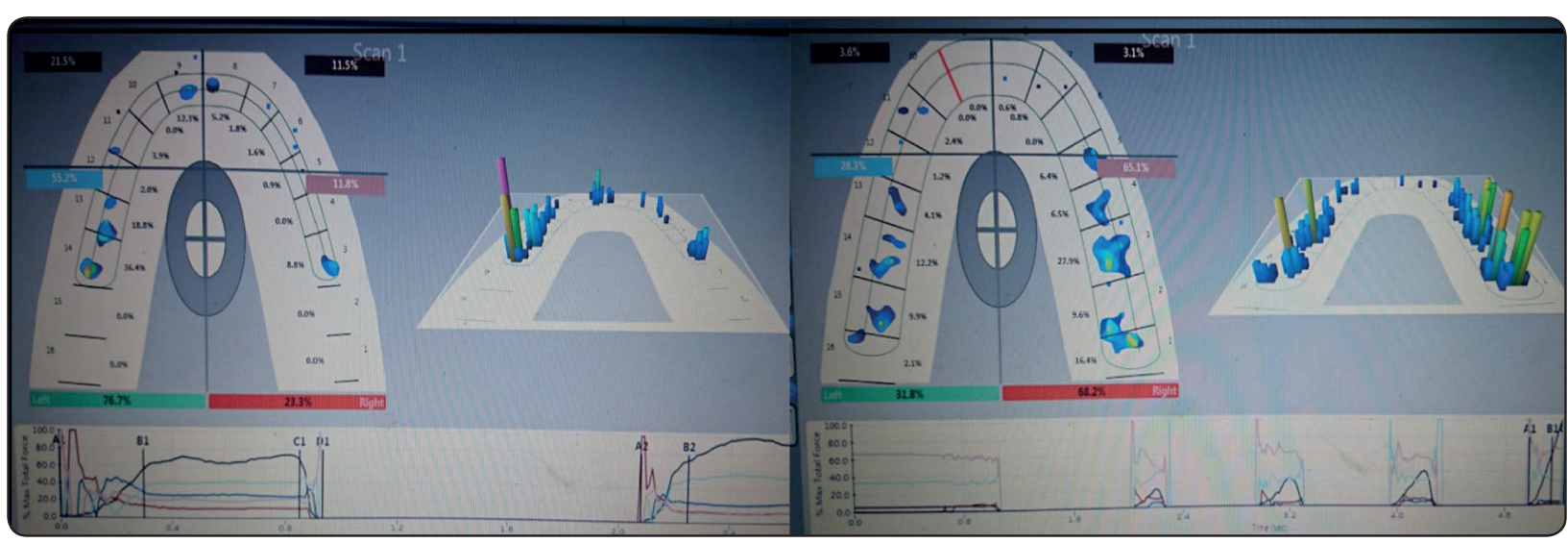

Fig. (2): Occlusal load distribution measurement by T scan III system

The measurements was done at time of prosthesis insertion, 3 months, 6 months, 9 months and 12 months after denture insertion.

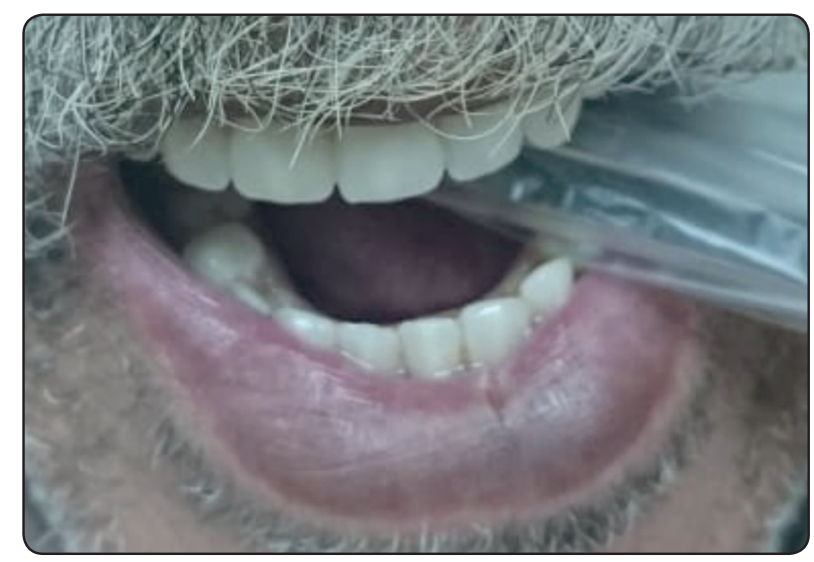

Fig. (3) Biting force measurement with load star sensor

\section{Statistical analysis}

Statistical analysis performed with SPSS $20^{\circledR *}$, Graph Pad Prism ${ }^{\circledR * *}$ and Microsoft Excel 2016 ${ }^{* * *}$ with significant level set at $\mathrm{P} \leq 0.05$. Data was presented as means and standard deviation (SD).

\section{RESULTS}

For evaluation of effect of biting forces for each group during twelve months follow up period, one way analysis of variance (ANOVA) followed by Tukey`s post hoc test for multiple comparisons which revealed there was insignificant difference for each group and between different follow up periods within each group as $\mathrm{P}$-value $>0.05$, as listed in table ${ }^{(1)}$.

Using independent $t$ test for comparison between both groups regarding biting forces, although the biting force for Group I (Mandibular Overdenture retained by locator attachment) was shown high biting force reading when compared with Group II(Mandibular Overdenture retained by ball attachment ) but there was insignificant difference between both groups at different follow up periods as ( $\mathrm{P}$ value $>0.05)$, as listed in table (1)

\section{Occlusal force analysis by using T-scan}

Data was presented Percentage (\%).T-scan analysis of group I revealed $8.5 \%, 11.2 \%, 35 \%$ \& $50 \%$ for right anterior, left anterior, right posterior 
\& left posterior segments respectively, while in group II revealed $17 \%, 18 \%, 28 \% \& 37 \%$ for right anterior, left anterior, right posterior \& left posterior segments respectively as presented in table (2)

Chi square test was performed to compare between two groups and revealed that group I was higher than group II regarding posterior segment with insignificant difference as $p>0.05$. On the other hand, group I was lower in occlusal load than group II regarding anterior segment with insignificant difference as $p>0.05$.

TABLE (1): Comparison between biting force in group I and group II during twelve months follow up period:

\begin{tabular}{|c|c|c|c|}
\hline Follow up & $\begin{array}{c}\text { Group I } \\
\mathbf{M} \pm \mathbf{S D}\end{array}$ & $\begin{array}{c}\text { Group II } \\
\mathbf{M} \pm \mathbf{S D}\end{array}$ & P-value \\
\hline At insertion & $135.72 \pm 41.491^{\mathrm{a}}$ & $107.17 \pm 33.885^{\mathrm{a}}$ & $\mathbf{0 . 1 0 5}$ \\
\hline $\mathbf{3}$ months & $135.83 \pm 37.281^{\mathrm{a}}$ & $107.21 \pm 32.917^{\mathrm{a}}$ & $\mathbf{0 . 0 8 4}$ \\
\hline $\mathbf{6}$ months & $135.95 \pm 43.741^{\mathrm{a}}$ & $107.29 \pm 35.561^{\mathrm{a}}$ & $\mathbf{0 . 1 1 8 4}$ \\
\hline $\mathbf{9}$ months & $136.12 \pm 45.936^{\mathrm{a}}$ & $107.31 \pm 31.239^{\mathrm{a}}$ & $\mathbf{0 . 1 0 0 9}$ \\
\hline $\mathbf{1 2}$ months & $136.29 \pm 42.843^{\mathrm{a}}$ & $107.38 \pm 30.986^{\mathrm{a}}$ & $\mathbf{1 . 0 0}$ \\
\hline P-value & $\mathbf{1 . 0 0}$ & & \\
\hline
\end{tabular}

M; Mean, SD; Standard Deviation, P; Probability Level,

TABLE (2): Occlusal load analysis by using t-scan in both groups:

\begin{tabular}{|c|c|c|c|c|}
\hline \multirow{2}{*}{} & \multicolumn{2}{|c|}{ Anterior teeth } & \multicolumn{2}{c|}{ Posterior teeth } \\
\cline { 2 - 5 } & Rt. & Lt. & Lt. \\
\hline Group I & $8.5 \%$ & $11.2 \%$ & $35 \%$ & $50 \%$ \\
\hline Group II & $17 \%$ & $18 \%$ & $28 \%$ & $37 \%$ \\
\hline Pvalue & 0.578 & 0.674 & 0.742 & 0.567 \\
\hline
\end{tabular}

Anti: anterior.Post: posterior.

Rt.: Right side.Lt.: Left side.

$\%$ : Percentage. 


\section{DISCUSSION}

In this study a male patients with upper conventional complete denture with opposing Mandibular implant retained Overdenture were selected with their age ranged from 55-60 years this close age range in order to eliminate age effect on the biting force and male patients were selected also to prevent the sexual variation specially in the power of biting force and muscle activity as some researchers reported that the lower values of bite force in women compared to men. (24)

All patients participating in this study exhibited Angle's class I ridge relationship to avoid subjecting the implants to abnormal forces. ${ }^{(25)}$

Patients with history of abnormal or para-functional habits as clenching and bruxism were excluded to avoid excessive load and undue concentrated forces on the implants. ${ }^{(26)}$

It has been reported that one of the main causes of osseointegration failure is lack of proper oral hygiene. Therefore, Patients with poor oral hygiene were excluded to avoid the risk of peri-implant mucositis and peri-implantitis.

The T-Scan can indicate premature contact and the force distribution on teeth, and provides measurable force and time information that ensures proper occlusal adjustment. In implant dentistry, the discovery of premature contacts allows early intervention to prevent future problems. As the biocompatible implants without periodontal ligament so it has not shock absorption criteria and cannot adapt according to the need of occlusal forces .So anticipated occlusal and biting forces need to be taken under consideration for any implant supported over denture in order to decrease the probability of failure either for the implant itself or for the attachment or even for the superstructure prosthesis. ${ }^{(27,28)}$

It was proven that during denture insertion, we can conduct the procedure of occlusal adjustment accurately using articulating paper with the aid of the T-scan III as the accuracy and ability to get repeat- able reading act as useful occlusal mapping device to record the exactly pattern of occlusion and allow more favorable occlusal load distribution. So our study was able to confirm the great benefits of the Tscan III and its manual usage. When the software and the sensor were used in a right way, registering occlusal contacts showed high accurate display of the contact points on the teeth measuring the force and the time on occlusion. ${ }^{(29-32)}$ Furthermore, the static coordinated occlusal contact of maximum number of teeth during maximum intercuspation leading to a simultaneous and equally distributed marginal bone loss around the implants preventing uneven forces and uneven bone loss in certain areas. It also aided in increasing the bone density and its stability around the implants preventing uneven forces and bone Resorption reaction in certain areas. ${ }^{(33,34)}$

Bite force is an important variable to investigate proper oral function which is related to occlusal factor, dentition, dentures, and treatment with implants, orthognathic surgery, temporomandibular disorders and neuromuscular changes. ${ }^{(35)}$

Regarding to the results of load distribution of this study revealed that the Overdenture with balanced occlusion, such as posterior balance force direct the force to the target area, and most of teeth contributing to occlusion. A significantly higher occlusal force percentage was found in the posterior region than the anterior region, which is in agreement with previous studies.

Moreover there was a slight difference in the bilateral force distributions which indicate the slight asymmetry, even in patients with normal occlusion may be attribute to the habitual occlusion. Also group I was lower in occlusal load than group II regarding anterior segment with insignificant difference as $p>0.05$. That may attribute to the stability and retention in Overdenture retained by locator attachment superior than those retained by ball and socket due to the dual retention action of the locators attachments. ${ }^{(33-35)}$ 
The Biting force and the number of functional teeth are directly related to the masticatory function as the measuring maximum bite force is attributed to the force quantity that elevator muscles can performed.The results of this study revealed that the maximum biting force was recorded in both groups while in group I treated by Mandibular over denture retained by locator attachment recorded more than those treated with Mandibular over denture retained by ball attachment (group II) However, this increase was not statistically significant that may be attribute to the nature of the locator attachment with parallel walls and flat occlusal top that may be increase retention and make limitation of the movement which may decrease the resilience of the attachment especially when compared with the ball attachment which considered the resilient attachment allow the universal rotation. Also the double retentive surface area "Dual retention" ensuring long-lasting retention life and allow increase biting and muscle force . $^{(36-38)}$

\section{CONCLUSION}

Within the limitations of this study and regarding the sample size and study periods, it was concluded that the Mandibular implant Overdenture with the locator attachment might be selected over Ball \& Socket attachment when designing a two implant retained Mandibular over dentures since it is more superior from the biting force point of view .

\section{REFERENCES}

1. Heydecke G, Locker D, Awad MA, Lund JP, Feine JS (2003) Oral and general health-related quality of life with conventional and implant dentures. Community Dent Oral Epidemiol 31(3): 161-168.

2. Feine JS, Carlsson GE (2003) Implant overdentures. The standard of care for edentulous patients. Quintessence, Chicago, USA.

3. Shor A, Goto Y, Shor K (2007) Mandibular Two Implant Retained Over denture: Prosthetic Design and Fabrication Protocol. Compen Contin Educ Dent 28(2): 80-89.
4. Thomason JM, Feine J, Exley C, Moynihan P, Müller F, et al. (2009) Mandibular two implant-supported overdentures as the first choice standard of care for edentulous patientsthe York Consensus Statement. Br Dent J 207(4): 185-186.

5. Abdelhamid AA, Metwally NA, Imam MH (2016) The Effect of Two Different Attachments with Implant Retained Mandibular Overdentures on the Masticatory Function. J Dent Oral DisordTher 4(2): 00101. DOI: 10.15406/ jdhodt.2016.04.00101

6. AlHarbi FA (2018) Mandibular implant supported over dentures : prosthetic overview. Saudi J Med Sci 6:2-7

7. Shor A, Goto Y, Shor K. (2007) Mandibular two-implant-retained overdenture: prosthetic design and fabrication protocol. Compend Contin Educ Dent; 28:80-88.

8. Cepa S, Koller B, Spies BC, Stampf S, Kohal R-J. (2016) Implant retained prostheses: ball vs. conus attachments - a randomized controlled clinical trial. Clin Oral Impl Res; 28:1-9.

9. Danesh-Meyer M. (2009) Implant retained mandibular overdentures using locator attachments on endosseous dental implants. Aust Dent practice,; Mar April, 122-124.

10. Buttel AE, Buhler NM, Marinello CP. (2009). Locator or ball attachment: a guide for clinical decision making. Schweiz MonatsscherZahnmed.119:901-918.

11. Agrawal N, Jain S, Agrawal D.A comparative evaluation of fatigue resistance of two different implant overdenture stud attachments with different denture base materials An invitro study (2018)J Indian Prosthodont Soc;18:10-8.

12. Kaneko T, Nakamura S, Hino S, Horie N, Shimoyama T. (2016) .Two-implant-retained overdentures using locator attachments in completely edentulous patients with severely resorted mandible: a report of two cases. J Dent App 3:315-318.

13. Eltaftazani I, El-Anwar MA.(2010) Locator attachment versus ball attachment: 3-dimensional finite element study. 88th ed. Barcelona, Spain.

14. Baba NZ, Al-Harbi FA, AlRumaih HS, AlShehri A (2019) .A Novel Extended Range Attachment System to Retain Implant Overdentures: A Clinical Report. J Prosthodont. 2019 Jan;28(1):3-9. doi: 10.1111/jopr.12907. Epub 2018 May 31.

15. Kurtzman GM. (2009). The locator attachment: Free standing versus bar overdentures. Dent Labor Int plus, Feb. 1;(1),20-23. 
16. Afrashtehfar, K. I. \& Qadeer, S. (2016). Computerized occlusal analysis as an alternative occlusal indicator. Cranio. 34, 52-57 .

17. El Mekawy N, ElhawaryMY.J (2019) Clinical evaluation of inter-implant distance influence on the wear characteristics of low-profile stud attachments used in mandibular implant-retained overdentures.Clin Exp Dent. Jan; 11(1):e33e41. Epub 2019 Jan 1.

18. Shastry T, Anupama NM, Shetty S, Nalinakshamma M. (2016). An in vitro comparative study to evaluate the retention of different attachment systems used in implant-retained overdentures. J Indian Prosthodont Soc 16:159-66.

19. Cerna, M., Ferreira, R., Zaror, C., Navarro, P. \& Sandoval, P. (2015). Validity and reliability of the T-Scan((R)) III for measuring force under laboratory conditions. J. Oral Rehabil. 42, 544-551 .

20. PyakurelU, Long H, Jian F, Sun J , Zhu Y, Jha H , Lai W(2013). Mechanism, accuracy and application of T-Scan System in dentistry-A review Journal of Nepal Dental Association Jan-July.

21. Qadeer, S., Yang, L., Sarinnaphakorn, L. \&Kerstein, R. B. (2016). Comparison of closure occlusal force parameters in post-orthodontic and non-orthodontic subjects using T-Scan(R) III DMD occlusal analysis. Cranio. 1-7 .

22. Hattori, Y. et al. (2009). Bite forces and their resultants during forceful intercuspal clenching in humans. J. Biomech. 42,1533-1538.

23. Sharma AJ, Nagrath, LahoriM. A comparative evaluation of chewing effecieny, masticatory bite force, and patient satisfaction between conventional denture and implant -support mandibular overdenture: An in vitro study . (2017). J Indian Prosthodont Soc 17:361-72.

24. Cune MS, van Kampen FM, van der Bilt A. (2006) Patient satisfaction with different types of implant-retained overdentures in the edentate mandible [in Dutch]. Ned Tijdschr Tandheelkd.113:401-407.

25. Helal E, El-Zawahry M, Gouda A, Elkhadem AH, Ibrahim SI. (2017) Bone Height Changes of the Mandibular Edentulous Ridge in Screw Retained Versus Telescopic Restorations for Completely Edentulous Patients. Maced J Med Sci. 5(1): 72-78.

26. Reddy SV, Kumar MP, Sravanthi D, Mohsin AHB, Anuhya V. Bruxism. A Literature Review. (2014) J Int Oral Health. 6(6): 105-109.
27. Kerstein, R. B. (2008) T-scan III applications in mixed arch and complete arch, implant -supported prosthodontics. Dent. Implantol. Update.19, 49-53.

28. Afrashtehfar, K. I. \& Qadeer, S. (2016) Computerized occlusal analysis as an alternative occlusal indicator. Cranio. 34, 52-57.

29. Bozhkova TP (2016) The T-SCAN System in Evaluating Occlusal Contacts. Folia Medica 58: 122-30.

30. da Silva Martins MJ, Caramelo FJ, da Fonseca JAR, Nicolau PMG.(2014) In vitro study on the sensibility and reproducibility of the new T-Scan_ III HD system. Rev Port Estomatol Cir Maxilofac.;55:14-22.

31. Garc_1a VG, Cartagena AG, Sequeros OG. (1997) Evaluation of occlusal contacts in maximum intercuspation using the T-Scan system. J Oral Rehabil.;24:899-903.

32. Koos B, Godt A, Schille C, G€oz G. (2010) Precision of an instrumentation-based method of analyzing occlusion and its resulting distribution of forces in the dental arch. $\mathrm{J}$ OrofacOrthop. 71:403-410.

33. Zayed MA, Shakal EA, Abutaleb FA (2018) The Effect of Computer Guided Occlusal Adjustment on Radiographic Outcome and Masticatory Efficiency of ImplantSupported Overdentures. J Oral Health Dent 2: 106. doi: 10.18875/2577-1485.2.106.

34. KhuderT ,Yunus N, Sulaiman E., Ibrahim N ,Khalid T. and Masood M. (2017).Association between occlusal force distribution in implant overdenture prostheses and residual ridge Resorption . Journal of Oral Rehabilitation 2017 44; 398-404

35. Van Der Bilt, A., Tekamp, A., Van Der Glas, H. \& Abbink, J. Bite force and electromyograpy during maximum unilateral and bilateral clenching. (2008) Eur. J. Oral Sci. 116, 217-222.

36. Hattori, Y. et al. Bite forces and their resultants during forceful intercuspal clenching in humans. (2009) J. Biomech. 42, 1533-1538.

37. JimohOlubanwo Agbaje1, Elke Van de Casteele, Ahmed S. Salem1, Dickson Anumendem, Eman Shaheen1, Yi Sun1 \&Constantinus Politis (2017). The T-Scan system in patients undergoing orthognathic surgery Scientific Reports । 7: 5356 | DOI:10.1038/s41598-017-05788.

38. Qadeer, S., Yang, L., Sarinnaphakorn, L. \&Kerstein, R. B. Comparison of closure occlusal force parameters in postorthodontic and non-orthodontic subjects using T-Scan(R) III DMD occlusal analysis. Cranio. 1-7 (2016). 
39. Abdelhamid AA, Metwally NA, Imam MH (2016) The Effect of Two Different Attachments with Implant Retained Mandibular Overdentures on the Masticatory Function. J Dent Oral DisordTher 4(2): 00101. DOI: 10.15406/ jdhodt.2016.04.00101

40. Bakke M, Holm B, Gotfredsen K (2002) Masticatory Function and Patient Satisfaction with Implant-Supported
Mandibular Overdentures: A Prospective 5-Year Study. Int J Prosthodont 15(6): 575-581. 36.

41. Mohamed Sobhy, Mohamed Abd-Elakher (2012) Effect of Different Attachment Size on the Muscle Activity in Single Implant Retained Mandibular Over denture. Current Science International 2(1): 18-20. 